\title{
A Hybrid Scatter Search Heuristic for Solving Cockpit Crew Rostering
}

\author{
Ahmad Rusdiansyah ${ }^{1 *}$, Danim Musthofa ${ }^{1}$, Nurhadi Siswanto², Maulin Masyito Putri ${ }^{3,1}$
}

\begin{abstract}
This research introduces the development of Hybrid Scatter Search Heuristic for solving cockpit crew (pilot and co-pilot) rostering problem. This research aims to minimize the deviation of flight hours among the cockpit crew of an airline, Garuda Indonesia Airline, during the one-month planning horizon. The weakness of the existing algorithm used in the airline, which is a trial-and-error algorithm, is that the variation among crew flight times for one month is too significant and the scheduling process takes a quite long time. We tested the performance of our proposed algorithm to that of the existing algorithm. The numerical experiments showed that the proposed algorithm had outperformed the existing algorithm. More specifically, we found some in sensitivity analysis experiments. Our experiment results showed that that the higher the flight time target, the higher the total deviation of flight time. We also conducted several experiments to show the robustness of our proposed algorithm. First, we tested the relationship between the number of pilots who can use their preferences and the total deviation of flight time. We conducted experiments by giving the cockpit crew the opportunity to choose a day off. Finally, we analyzed the results by changing the number of cockpit crew.
\end{abstract}

Keywords: Cockpit crew, scatter search heuristic, crew rostering.

\section{Introduction}

The airline industry is a kind of industries that require a high operational level and complexity. The operation of an airline can be executed without difficulty if it is supported by the availability of aircraft fleet, fuel, crew, and many other supportive aspects. Every aspect mentioned above entail a significant cost and produce a high level of risk that must be covered by the airline. Among the costs involved, the crew costs are the second largest expense after the fuel procurement cost, amounting about $15-20 \%$ of the overall operational cost (El Moudani et al. [1]). Thus, one of the efforts to increase the profit margin of an airline company is to reduce the crew cost. Accordingly, Kohl and Karisch [2] mentioned that the planning of aircraft crew is an essential factor for an airline company to reduce its operational cost. Bazargan [3] explained that an amount of savings in flight-crew expense through better scheduling could produce millions of dollar savings. Because of this considerable attention from both academicians and industries.

\footnotetext{
1 Transportation and Distribution Logistics (TDLog) Research Group, Department of Industrial Engineering, Institut Teknologi Sepuluh Nopember, Jl. Raya ITS, Keputih, Sukolilo Surabaya, 60111 Indonesia. Email: arusdian@ie.its.ac.id, denim.musthofa@yahoo.com

2 Department of Industrial Engineering, Institut Teknologi Sepuluh Nopember, Jl. Raya ITS, Keputih, Sukolilo Surabaya, 60111 Indonesia. Email: nurhadi.siswanto@gmail.com.

${ }^{3}$ Department of Logistics Engineering, Universitas Internasional Semen Indonesia, J. Veteran, Sidokumpul, Gresik, 61122 Indonesia. . Email: maulin.putri@uisi.ac.id

* Corresponding author
}

There are two types of airline crew scheduling problems which are cockpit crew (pilots and co-pilots) scheduling and cabin crew scheduling.

In literature, crew scheduling problem is known as one of the most difficult combinatorial problems (Barnhart [4]). The purposes of crew scheduling problem are varied such as minimizing operational of crew costs, equalizing crew workloads, and maximizing opportunities of the crew in choosing their preference schedules. Some constraints should be considered including the standards or policies stated by the government and international aviation union. To solve the crew scheduling problem, it should be decomposed into two sub-problems. Two subproblems are crew pairing and crew rostering. It is caused by several reasons, including the difficulty to solve the whole problem simultaneously (see Soykan and Erol [5]).

Crew pairing phase is conducted to find a set of round-trips and the duty for each specific flight period that has been set. Crew pairing is conducted without considering the crew's individual preference. The problems in the crew pairing of an airline are subject to the regulation (Maenhout and Vanhoucke [6]). A crew pairing set contains the flight numbers that use the same aircraft, starting and ending at the crew's home base. In the second phase, crew rostering or also called crew assignment, is a process of assigning a crew member individually into crew pairing set that has been previously determined. It is usually scheduled for a one-month planning horizon. Government authority's regulations, union aviation 
agreements, the internal regulation of airline and pre-assigned activities (vacation, leave, training) are several factors that influence the crew rostering phase. The crew rostering problem usually aims not only to minimize costs but also to maximize the social performance quality of the crew, by balancing the crew total flight time and flight preferences. The crew rostering is generally carried out for two to six weeks before the flight is scheduled. Compared to the crew pairing issue, the problems in crew rostering have received less attention in the academic literature (Maenhout and Vanhoucke [6]).

It is known that crew rostering is a combinatorial problem which is extremely difficult, because several constraints must be considered, meaning that for solving these problems can create a model that is very complex. Because of the possibility of very long and time-consuming solutions, the most widely used method is heuristic (El Moudani et al. [1]).

In this research, we propose a heuristic called Hybrid Scatter Search for solving the cockpit crew rostering problem. The objective function of the problem is to minimize the deviation of flight hours among the cockpit crew of an airline during a planning horizon. Specifically, we conduct several experiments using a real case of cockpit crew scheduling (Chief Pilot and First Officer) on Garuda Indonesia Airline for the aircraft type Airbus A330 during a month.

In the practice of this airline, the algorithm used for crew rostering is a trial and error algorithm using a "day-by-day" or "pilot-by-pilot" algorithm. The dayby-day algorithm is conducted by assigning crews who are available on the first day and then assigning crews who are available on the second, and so on. Meanwhile, in the pilot-by-pilot algorithm, crew assignment is conducted for the first crew, and then the second crew, and so on. However, by using such a greedy algorithm, the variation among crew flight times for one month is too significant, in addition to which the scheduling process takes quite a long time.

\section{Methods}

\section{Crew Scheduling Problem}

Crew scheduling is an identification process to arrange the flight schedule by assigning duties to the cockpit and cabin crew (Bazargan [3]). Crew scheduling in an airline has different aims, including minimizing the operational costs of the crew, levelling the workload of the crew, or giving the crew the freedom to determine their assignments themselves regarding both times, destination, and co-workers, which can improve the performance by giving the best service to customers. Moreover, scheduling of the crew must be subject to many rules that have been established by government regulations, agreements with the aviation union to ensure the quality of life of the crew, or rules that are set explicitly by airlines to improve their service quality (Ernst et al. [7]).

Airline regulations are made to assure the safety of the flight by ensuring that the crew members are not working under pressure. With these considerations, the airline company makes sure that the crew members get a suitable connection time between flights, sufficient layover period, and reasonable flight hours each day. The airline regulation also arranges a minimum number of crews assigned to each flight. Through their union, the crew members can negotiate minor work rules related to the start and end of each duty period, vacation days, and so on. An airline can also add internal rules to its crew members in addition to the rules mentioned above (Abdelghany and Abdelghany [8]).

In general, the cockpit crew is trained and certified to fly a specific aircraft type. Due to the safety of the flight, the cockpit crew cannot operate more than one aircraft-type at the same time. Moreover, the cockpit crews are grouped based on the seniority of the captain (CP) and the co-pilot or first officer (FO), and in some cases the existence of a second officer (SO). The fleet type and the position of each cockpit crew are determined, whereas the flight attendants can be assigned to more than one fleet type, in which they are trained to serve passengers in a wide- or narrowbody aircraft (Abdelghany and Abdelghany [8]). Due to such complexities, the problem of crew scheduling is accomplished in two phases, namely crew pairing and crew rostering.

\section{Crew Pairing}

Crew pairing is a phase that contains the flight sequences using the same fleet in which the start and end at the same crew home base. The crew home base is the city or a place where the crew lives (Bazargan [3]). Each pairing consists of a cockpit crew and a cabin crew. Crew pairing is conducted to find a set of round-trips and to meet the requirements for a specific flight period. Crew pairing is conducted without considering individuals' needs or the crew's wishes. The problems faced by crew pairing of an airline are different depending on the regulations set by the airline (Maenhout and Vanhoucke [6]).

The following gives several definitions used in crew pairing problems (see Bazargan [3]) (see Figure 1):

Crew connection: a link between flights, where activities included are waiting time, crew replace- 


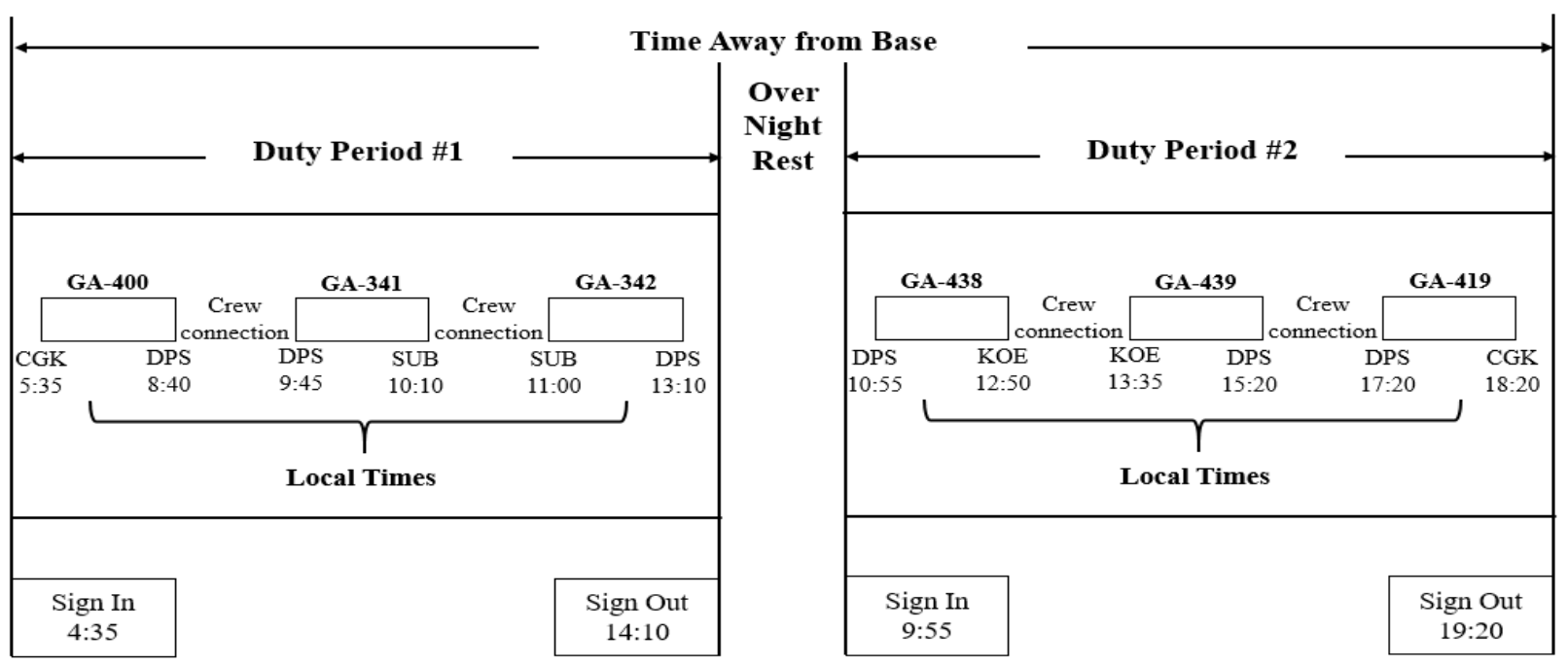

Figure 1. A Typical Pairing with Duty Periods, Crew Connection within Duty Periods, Overnight Rests, and Sign-In and Sign-Out Times. Adopted from Bazargan [3]

ment, and fleet replacement for the next flight schedule. Usually, the sit connection time of an airline is between 10 minutes and 3 hours.

Rest period: an interduty connects or overnight rest.

Moreover, according to Abdelghany and Abdelghany [8], the following regulations are usually considered within the flight operations: (1) The maximum length of duty may not exceed the established maximum standard. (2) There is a minimum rest period given between two duty periods. (3) The layover time should not exceed the maximum duration (usually 36 hours). (4) The ground time between two flights in the same duty period should be greater than the minimum standards. (5) The crew's income is determined based on their work time, flight hours, and the length of time that they are away from the base. (6) The crew gets a per diem for each layover period away from the home base. (7) The crew will receive a bonus if the total time away from the home base exceeds the maximum standard.

\section{Crew Rostering}

Crew rostering is a process to assign crew members individually to the crew pairing that has been obtained and is generally conducted for a one-month planning horizon (Bazargan [3]). Crew rostering is generally not only conducted with the aim of minimizing crew costs but also to maximize the crews' social quality. Crew rostering is conducted for 2 to 6 weeks before the flights (Ernst et al. [7]).

There are two different approaches to the implementation of crew rostering, namely bid-line rostering and personalized rostering. In bid-line rostering, each roster is arranged for some pairings, vacation activity, standby, reserve, and training slots. Then, every crew member is assigned to the anonymous roster based on seniority. Any member of the crew can choose a roster by following the tasks and holiday they want within one month. In personalized rostering, every roster is assigned directly to a member of the crew. The roster is made by meeting the wishes expressed by the crew members. Sometimes, the wishes of one crew member conflict with those of other members, thus rules must be applied fairly to ensure the roster is fulfilled with the minimum list of the crew's wishes. Therefore, in the bid-line rostering approach, crew members know the right roster is assigned to them (Abdelghany and Abdelghany [8]). While in personalized rostering, crew members do not know about the decision to be received after they offer their needs (Abdelghany and Abdelghany [8]).

The input for a crew rostering problem consists of general crew information, activities to be rostered, rules and regulations, and the objectives of scheduling. Generally, the crew information needed for crew rostering includes personal crew data (e.g. flight time, training), qualifications (seniority, list of flight destinations, language skills, and competency), preassigned activities (office duty, training, medical check), and vacations. The set of activities that are assigned to the crew consists of pairing, reserve duty, and pre-assigned activity. The rules of crew assignment are divided into horizontal, vertical, and artificial. The horizontal rule only applies to one roster and crew member. Thus, it does not consider any other rosters in the solution. A vertical rule concerns more than one roster and crew member. 
In many cases, this rule does not only depend on one roster but also consider on the overall schedule. A combination of the horizontal and vertical rules is called an artificial rule. This rule can represent an additional constraint used to disregard a wrong feasible solution, as well as to obtain a better solution.

One of the critical issues in the airline crew rostering problem is the sum of the deviation from standard working time for each crew member, which means fairness among all crew members (Doi et al. [10]). Fair working conditions have been studied as a performance index using as measures of the sum of fair working time the fair number of the days off (rest days) and the number of weekend shifts (Lucic and Teodorovic [11] in Doi et al. [10]).

\section{Algorithms}

In this research, we employ an algorithm called Hybrid Scatter Search heuristics to solve the crew rostering problem. We slightly modify the original Scatter Search algorithm to fit with the problem. The Scatter Search algorithm has been proved successfully to solve a diverse array of optimization problems from both classical and real-world settings (Glover and Laguna [12]). The framework of the Scatter Search method follows the development of alternative implementation with varying degrees of sophistication. According to Laguna and Marti [14], the Satter Search consists of five steps as follows:

\section{Diversification Generation Step}

The diversification generation step is used to generate the basis of diverse solution data for the initialization of searching. The most effective means of diversifying is if we can create an initial solution that is balanced in distinction and quality. It has been proven that the scatter search generates better results when the diversification generation step is not purely random, and solutions are determined by both the size of diversification and the objective function.

\section{Improvement Step}

The improvement step changes solutions with the purpose of improving the quality or the feasibility. The input for the improvement method is a single solution that may or may not be feasible. The output of the solution does not have to be better than the previous solution. Generally, the improvement step conducts the local search with the usual rule to immediately stop if there is no improvement detected to the current solution. The final result of the improvement step is a choice between the need to control the length of computational time required to fix solutions and the time spent outside the improvement step.

\section{Reference Set Update Step}

The reference set is a collection of both high-quality solutions and diverse solutions that are used to generate new solutions by applying the combination of the solution method. Specifically, the reference set consists of the union of two subsets RefSet 1 and RefSet $_{2}$ of size $b_{1}$ and $b_{2}$ respectively. That is, $\mid$ RefSet $\mid=b=b_{1}+b_{2}$.

The construction of the initial reference set starts with the selection of the best $b_{1}$ solutions from $P$. These solutions are added to RefSet and deleted from $P$. For each improved solution in P-RefSet, the minimum of the Euclidean distance to the solutions in RefSet is computed. Then, the solution with the maximum of these minimum distances is selected. This solution is added to RefSet and deleted from $P$, and the minimum distances are updated. This process is repeated $b_{2}$ times. The resulting reference set has $b_{1}$ high-quality solutions and $b_{2}$ diverse solutions.

\section{Subset Generation Step}

The subset generation generates subsets of the solution reference that become input to the combination method. Generally, the implementation of this method consists of the integration of all possible solution pairs. However, the implementation of scatter search is, in many cases, limited to operating on pairs of solutions. Thus, no contextual information is needed to apply the subset generation method.

The subset generation generates a subset that is used to create a new solution generation method. The subset generation is designed to generate the following subsets:

1. All 2-element subsets

2. 3-element subsets derived from the 2-element subsets by augmenting each 2 -element subset to include the best solution, not in this subset

3. 4-element subsets derived from the 3-element subsets by augmenting each 3-element subset to include the best solution, not in this subset

4. The subsets consisting of the best $i$ elements, for $i=5$ to b.

\section{Solution Combination Step}

The solution combination uses the generated subsets to combine the elements in each subset with the purpose of creating new trial solutions. Generally, the solution combination is a problem-specific mecha- 
nism, since it is directly related to the solution representation. Depending on the specific form of the combination of the solution method, each subset can create one or more new solutions.

\section{Model Formulation}

The mathematical model of crew rostering in this research is developed based on the master rostering problem by Kohl and Karisch [2] and adjusted to the existing situation of an airline company. The objective function of this model is following the model formulation by Bazargan [3], while the considered constraints are constructed based on the Basic Operation Manual of Garuda Indonesia for Airbus A330 aircraft [15].

\section{Notation:}

\section{Set}

$A$ : Activities to be scheduled (scheduled duty time or day off for 3 crew pairings)

$R$ : Rosters to be scheduled, crew rostering is the process of assigning individual crew members to the crew pairing that has been obtained). The number of rosters is equal to the total number of cockpit crews available

$P \quad$ : Types of cockpit crew's skills as pilot or copilot

$D$ : Scheduling time horizon (one month $=31$ days)

C : Available cockpit crew members (258 crew)

\section{Index}

$i \quad: \quad$ Activity index $(i \in A), i=1$ - in duty, $i=0$ a day off

$j$ : Roster index $(j \in R)$. The number to be rostered in this research is $258, j=$ $1,2, \ldots, 258$

$k \quad$ : Skill of cockpit crew index $(k \in P), k=1$ is pilot, $k=2$ is co-pilot

$l \quad: \quad$ Period index $(l \in D), l=1,2, \ldots 31$

$r:$ Cockpit crew index $(r \in C) ; r=1,2, \ldots, 258$

\section{Parameters}

$y_{r j}=1$ if cockpit crew $r$ is assigned to roster $j, 0$ otherwise

$f_{i} \quad$ : $\quad$ Flight time of activity $i$

$w_{l k}=1$ if period $l$ is done by type of cockpit crew skill $k, 0$ otherwise

$b_{r k}=1$ if cockpit crew $r$ is classified as cockpit crew with skill $k, 0$ otherwise

$u_{r} \quad$ : Age of cockpit crew $r$

$T_{l} \quad$ : Flight time limit of cockpit crew for period l

$D_{l}$ : Assigned day limit of cockpit crew for period $l$

$C_{k} \quad$ : Available cockpit crew for skill of cockpit crew $k$
$K \quad$ : Number of available cockpit crews

$h \quad$ : Target of flight time for each cockpit crew member. Target flight time is obtained from the average crew flight hours of the total time required to run 18 pairings in one day then multiplied by 31 days ( 1 month) and divided by the number of cockpit crew members.

\section{Decision variable}

$x_{i j l}=1$ if roster $j$ on period $l$ is covered activity $i$, 0 otherwise

The activity $(A)$ consists of 18 pairing activities (duty time) and non-pairing activities (day-off). The number of rosters to be scheduled is equal to the total of available cockpit crews, as many as $258 \mathrm{crew}$ members, where 253 crew members are assigned for flight activity (130 pilots and 123 co-pilots) and five crew members are assigned as ground crew (3 pilots and 2 co-pilots). This scheduling only considers the cockpit crews who are assigned flight activity. The output of the crew rostering is duty time, days off, and the number of flight hours.

\section{Objective Function:}

The objective function of this mathematical model is to minimize the total deviation of the cockpit crew's flight time.

$\min \sum_{j}\left(\sum_{l} \sum_{i}\left|x_{i j l} . f_{i}\right|\right)-h$

\section{Constraints:}

The workload of the cockpit crew

$\sum_{i} x_{i j l}=1$

$\sum_{j} y_{r j}=1$

The constraints of the cockpit crew workloads are made to ensure that each cockpit crew member is assigned to one roster (2) and one roster each day only covers one activity (3).

Crew flight time

$\sum_{l} \sum_{i} x_{i j l} . f_{i} \leq T_{l}$

This constraint of crew flight time is made to ensure that each crew member on consecutive days is assigned to a flight time that does not exceed the limits of the set flight time, i.e. 8 hours in every 24 hours, 30 hours in every week, 110 hours in every month, 1050 hours per year.

The number of assignment days

$\sum_{l} \sum_{i} x_{i j l} \leq D_{l}$

The constraint for the number of assignment days is made to ensure that on consecutive days the cockpit crew does not exceed the set assignment day limit; 


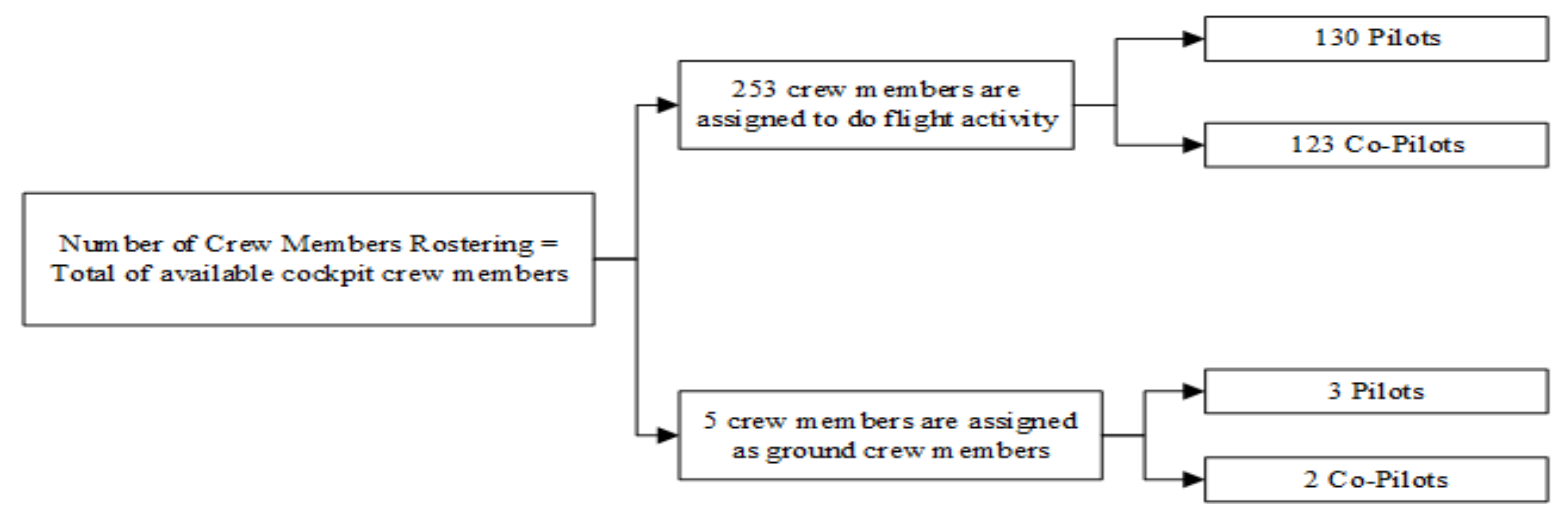

Figure 2. Number of Crew Rostering

for example, within seven days a crew member is assigned maximum five consecutive days of duty time and should have at least two days off.

The composition of the cockpit crew

$\sum_{k} \sum_{i} x_{i j l} \cdot w_{l k}=k$

The constraints of cockpit crew composition are made to ensure that each activity assigned to a pilot in each period also assigned to a co-pilot.

The number of cockpit crew members

$\sum_{r} \sum_{j} \sum_{i} x_{i j l} y_{r k} b_{r k} \leq C_{k}$

The constraint for the number of cockpit crew members is made to ensure that the number of cockpit crew members does not exceed the available schedule, for each activity on each roster, in each period.

The age of cockpit crew members.

$\sum_{k} \sum_{r} \sum_{j} \sum_{i} x_{i j l} y_{r k} u_{r} w_{l k} \leq 115$

This constraint is to ensure that the total age of the scheduled cockpit crew members is not exceeding 115 years. The age of all A330 cockpit crews should be less than 60 years. This constraint is compulsory. However, the constraints of the crew's age limit can be ignored because all A330 cockpit crews are less than 60 years old.

\section{Development of Hybrid Scatter Search Heuristic}

Pairing data is used as an input in the scheduling process. After obtaining the required data, the next step is to determine the parameters which affect the scheduling of the cockpit crews. These parameters include the number of initial solutions $(P)$, the reference set value consisting of RefSet 1 and RefSet2, and the maximum number of iterations.
The determination of initial solutions $(P)$ does not have specific rules. In this research, the number of initial solutions $(P)$ is defined as five solutions. Morevoer the reference set is defined with three solutions. The two best solutions that have the smallest total deviation of flight time are included in RefSet 1 while the worst solution with the largest total deviation of flight time is included in RefSet 2 .

In determining the reference set, Glover and Laguna [12] state that the reference set should be less than 20 solutions. The maximum number of iterations is 10 iterations. Determining the number of iterations has no specific rules, but the more iterations, the chance to get the near optimal solution is increasing.

The first stage of scatter search algorithm is the diversification step. At this stage, all pairs are randomly assigned to each roster by considering the minimum number of days off. The random process is run until five initial solutions obtained.

The next step is to choose a solution with the largest (worst) total deviation of flight time from five initial solutions that have been selected. The worst solution that has been chosen will be improved in the stage of improvement method.

The improvement step is then used to calculate the total deviation of flight time for each roster. The roster with the smallest deviation is used as the main solution to replace the previous main solution. A new main solution replacement is run until no constraints are violated. Then, the total deviation of flight time for the new solution is calculated again, and the results are compared with the results of the solution before the improvement step. If the new solution is better than the old one, then the new solution replaces the worst solution. However, if the new solution is not better than the previous solution, then the former solution is used.

The next stage is a reference set update step. This stage makes a comparison of the solutions that have 
been obtained at the previous stage. The two best solutions (a1 \& a2) are included in RefSet1. Meanwhile, one of the worst solutions (b1) is included in RefSet2.

The next stage is the process of the subset generation step. This step creates a subset type 1 by specifying the combination between reference sets including a1a2, a1b1, and $a 2 b 1$, and the subset type 2 , which specifies a combination of solutions $a 1 a 2 b 1$.

After specifying a combination in the subset generation steps, then proceed to the solution combination method, where the best result of the subset type 1 is chosen and combined with one of the other solutions by ensuring that the solution is not repeated in combination to get a type 2 subset.

Results between subsets type 1 and type 2 which have the smallest total deviation of flight time are selected then compared with solutions on the reference set. If the new solution for the combination method solution is better than the old one, then the new solution will replace the worst solution on the reference set. If the number of iterations is the same as the maximum iteration, then the best process is stopped and take the best solution from the last five solutions.

If the iteration has not reached the maximum iteration or the new reference has not found at the stage of the reference set update method, then repeat the improved method until one of both conditions is fulfilled. Figure $3 \mathrm{a}, 3 \mathrm{~b}, 3 \mathrm{c}$ explain the flowchart of scatters search algorithm development.

\section{Results and Discussions}

In this section, we compare the performance of the Hybrid Scatter Search algorithm with that of the current trial and error algorithm. We do sensitivity analysis includes the flight time target, the usage of crew preference implementation, and cockpit crew number.

\section{Comparison}

In the numerical experiments, we compared both algorithms to solve a real case of crew rostering problem in Garuda Indonesia Airline. We need to schedulele 253 cockpit crew of Airbus A330 fleet including 130 pilots and 123 co-pilots. The flight times of each cockpit crew is 54.79 flight hours per month. The maximum flight time of the cockpit crew is 110 flight hours per month.

The trial and error algorithm produce total deviation of flight time about 3147.68 hours and the average flight time of crew is 12.44 hours per day.
Meanwhile, the Hybrid Scatter Search algorithm produces a total deviation of flight time 1833.79 hours and the average flight time is 7.25 hours per day. These results showed that the Hybrid Scatter Search heuristic outperformed the trial and error algorithm of Garuda Indonesia.

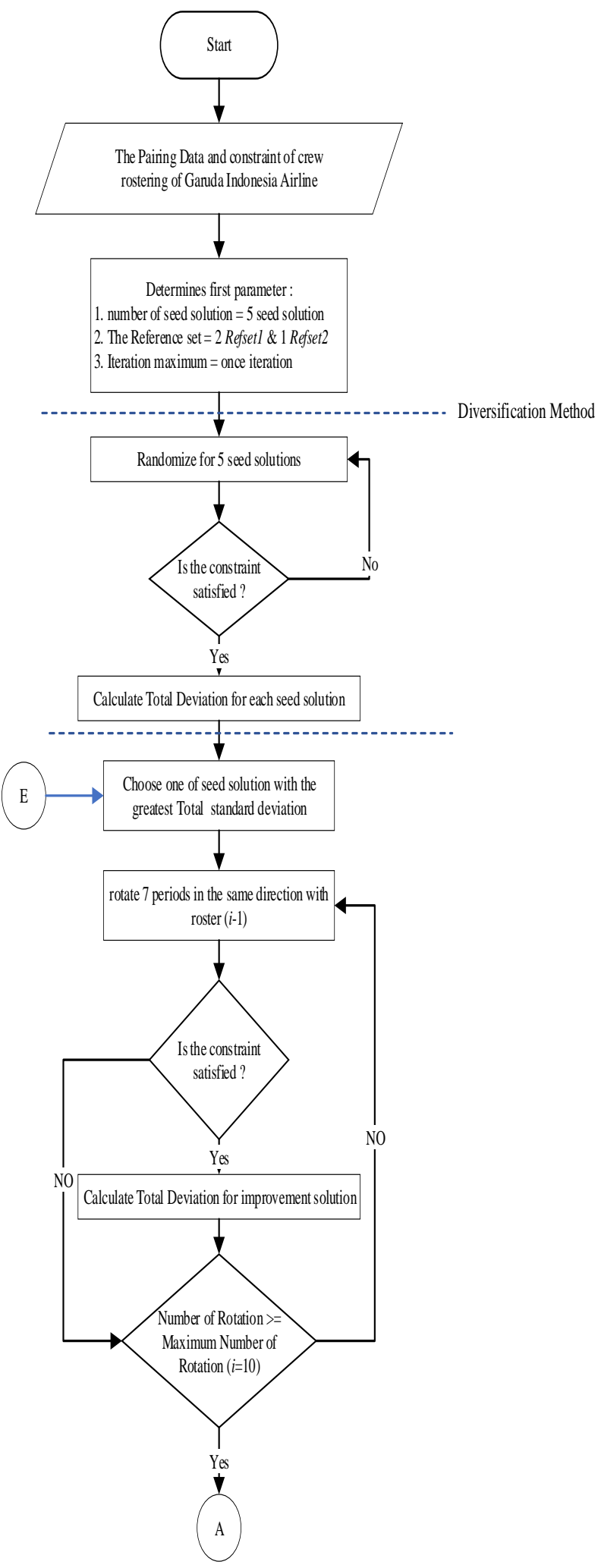

Figure 3a. Flowchart of Hybrid Scatter Search Algorithm 


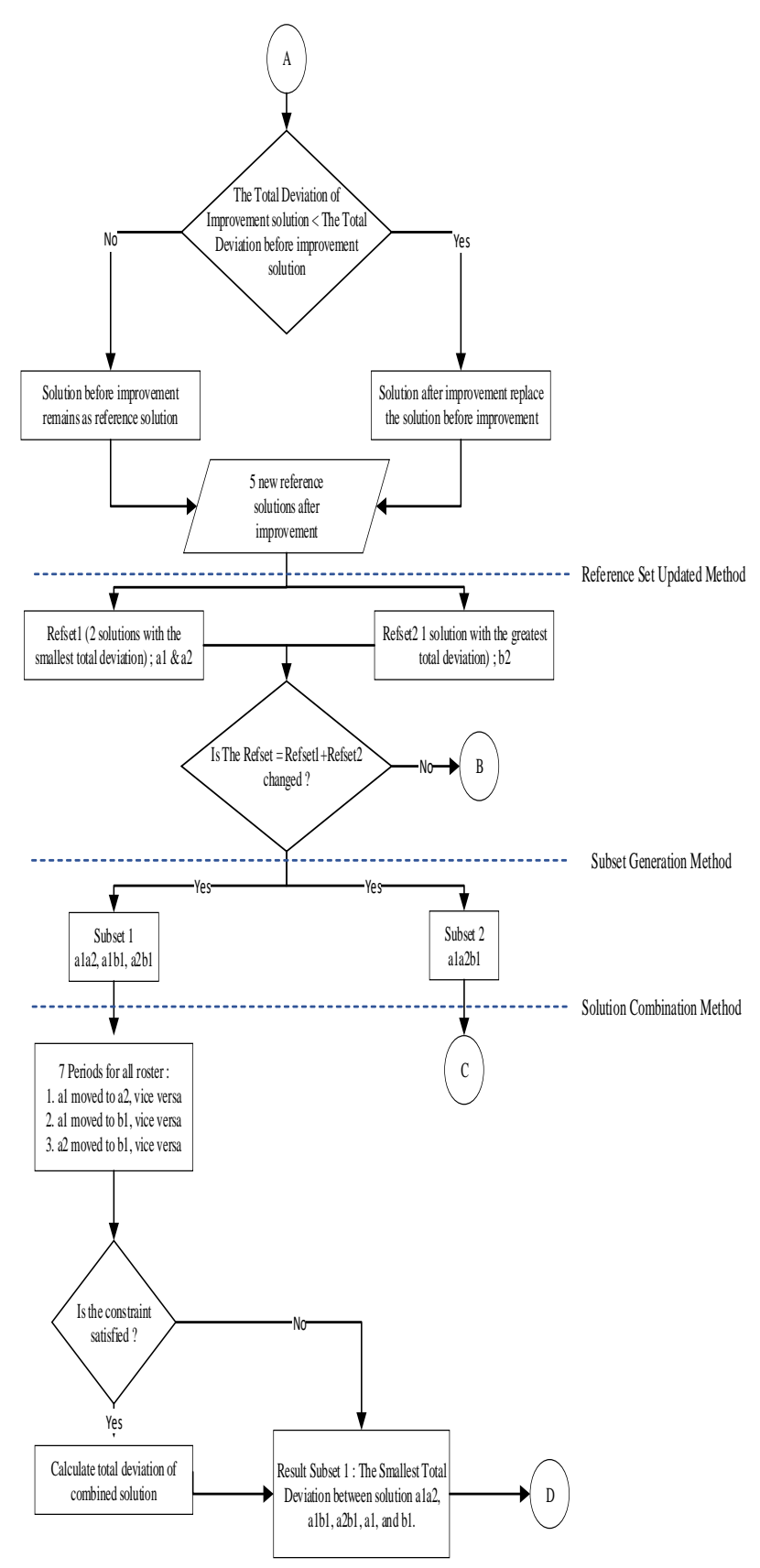

Figure 3b. Flowchart of Hybrid Scatter Search Algorithm (continued)

Additionally, the detailed statistic of both algorithms can be seen in Table 1 . The number of crews does not exceed the target of flight time. The proposed heuristic algorithm was computed using Matlab, and it took 435.39 seconds to proceed the algorithm.

\section{Sensitivity Analysis on Flight Time Target}

We do a numerical experiment by changing the flight time of crew. It is based on the average flight time of crew for one month (54.79 hours). We changed the target flight time to 55 hours, 56 hours and 57 hours. From the numerical experiment, we conclude that the total

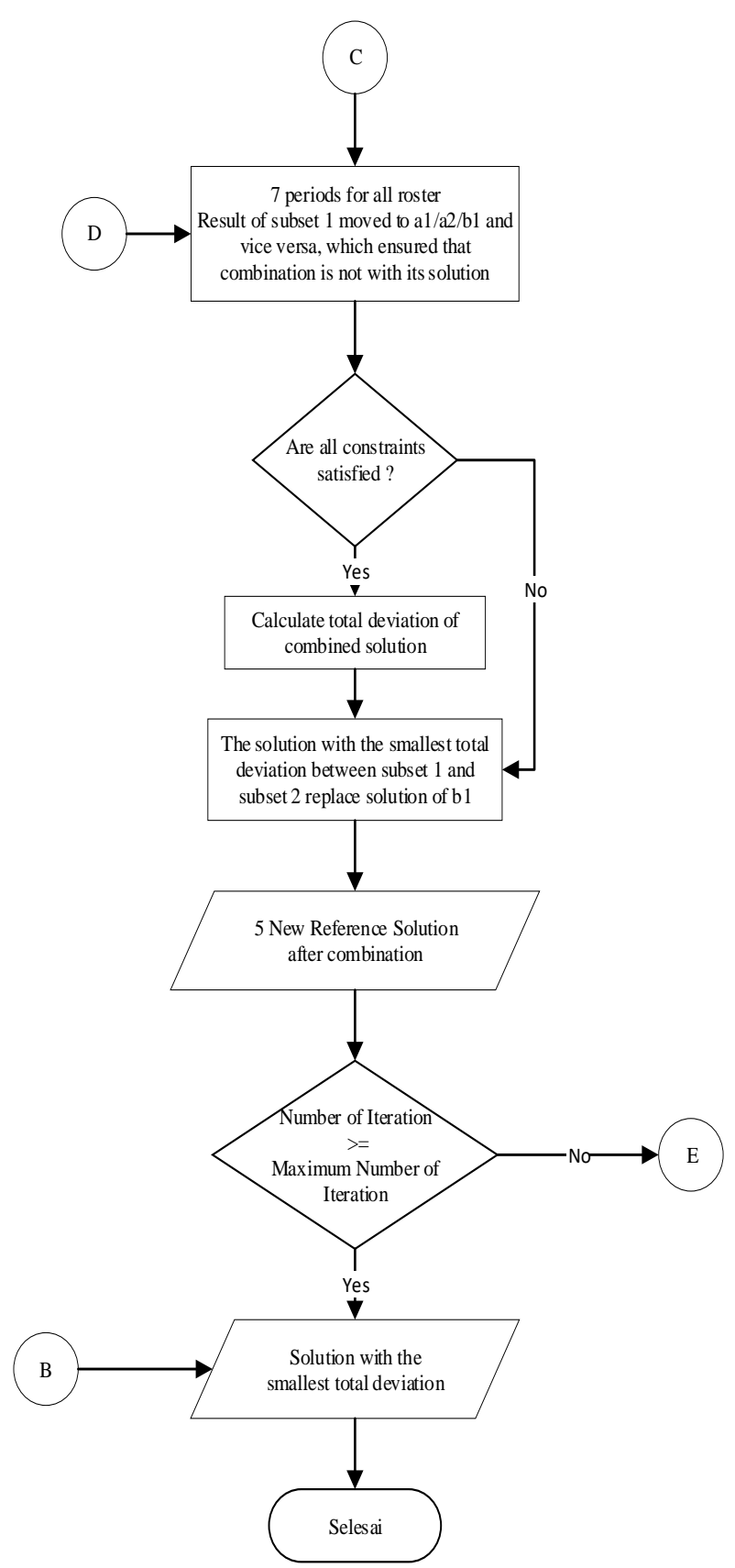

Figure 3c. Flowchart of Hybrid Scatter Search Algorithm (continued)

standard deviation of flight time increased when the flight time target has been increased (see Table 2).

\section{Analysis on Implementation of Crew Preferences}

This section explains the relationship between the implementation of crew preference policies to the total deviation of flight time. Crew preference is one of the airline's policies that provide the opportunity for the crew, especially for pilots to choose the flight assigned to them. The pilots can choose at least one duty every month and one day off every three months. 
Table 1. Results comparison

\begin{tabular}{lrr}
\hline \multicolumn{1}{c}{ Factors } & $\begin{array}{c}\text { Trial \& error } \\
\text { algorithm } \\
\text { (hours) }\end{array}$ & $\begin{array}{c}\text { Hybrid scatter } \\
\text { search algorithm } \\
\text { (hours) }\end{array}$ \\
\hline $\begin{array}{l}\text { Total deviation of flight } \\
\text { time }\end{array}$ & 3147.68 & 1833.79 \\
$\begin{array}{l}\text { Average flight time per } \\
\text { day }\end{array}$ & 12.44 & 7.25 \\
Maximum flight time & 103.42 & 83.83 \\
Minimum flight time & 13.35 & 33.17 \\
$\begin{array}{l}\text { Range flight time } \\
\text { Standard deviation of }\end{array}$ & 90.07 & 50.67 \\
flight time & 15.97 & 9.12 \\
Total crew with flight & 202 crews & 128 crews \\
time more than the & & \\
target & &
\end{tabular}

Table 2. Flight time target vs total deviation of flight time

\begin{tabular}{cc}
\hline Flight time target & Total deviation of flight time (hours) \\
\hline 55 hours & $1,833.67$ \\
56 hours & $1,854.33$ \\
57 hours & $1,903.83$ \\
\hline
\end{tabular}

Table 3. Total number of pilots using preference vs total deviation flight time.

\begin{tabular}{cc}
\hline $\begin{array}{c}\text { Total number of five pilots } \\
\text { using the preference }\end{array}$ & $\begin{array}{c}\text { Total deviation of flight ti } \\
\text { (Hours) }\end{array}$ \\
\hline 1 & 1832.46 \\
2 & 1831.13 \\
3 & 1831.13 \\
4 & 1832.46 \\
5 & 1833.88 \\
\hline
\end{tabular}

We conducted a numerical experiment for the crew preference by determining 1-5 pilots who can choose duty time or day off. The schedule is flexible, even the duty time or day-off is enforced to the scheduled flight. Here, each cockpit crew allow to choose a day off for one week, change the assigned pairing to their preferences. Table 3 shows the relationship between the number of pilots who can use their preferences and the total deviation of flight time.

This occurs because the cockpit crew members' days off differed from the ones initially set by shifting the pairing assigned for the desired day off by the cockpit crew. The shifting of that pairing shifted the time pairing assigned to the closest roster that has the least flight time during the month.

\section{Sensitivity Analysis on the Number of Cockpit Crew}

In this numerical experiment, the changing parameter is the number of cockpit crews available with the assumption that the composition of the pilot and co-pilot is one by one. By considering the minimum day off for each duty time in a sequential period, it is determined that every week the cockpit crew is assigned to a maximum of 2 pairings. Thus, in the one-month scheduling horizon, each cockpit crew is assigned to a maximum of 9 pairings.

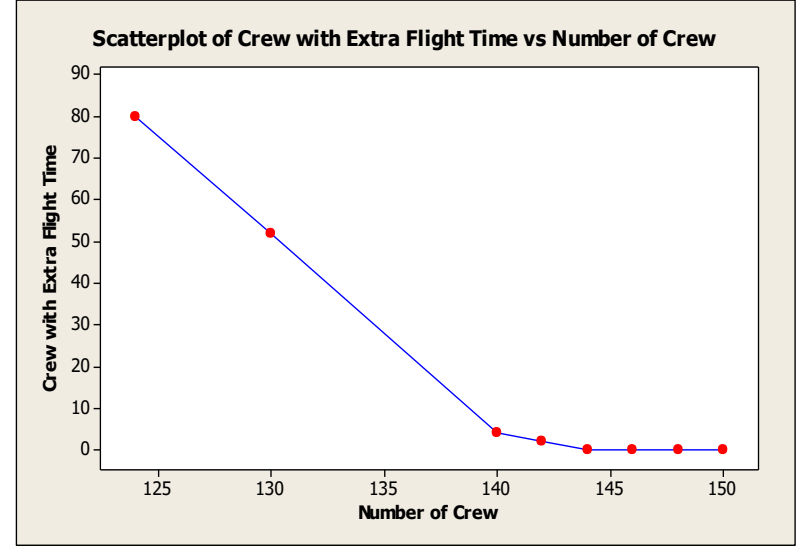

Figure 4. The relation between the total available cockpit crew members and the cockpit crew with the target exceeded flight times.

The minimum number of crews obtained from the calculation of the number of pairings assigned, i.e. 558 pairs for each cockpit crew composition, divided by the maximum pairing assigned to each cockpit crew. The minimum number of crews is 62 crews for the pilot and co-pilot respectively. We conducted a numerical experiment by changing the number of available crew of 124,130, 140 and 150 cockpit crews. The availability of 124 to 150 cockpit crews on an Airbus A330 aircraft can cover all pairings and do not violate existing constraints.

Based on the sensitivity analysis by changing the available cabin crews, we found that it needs 150 crew members so that the flight time of each cockpit crew do not exceed the total flight time. However, if we changed the availability of crew members between 140 and 150, there is a possibility that some crew members exceed the target of flight time.

Therefore, we re-examined the sensitivity analysis by changing the cockpit crews' number as follows: $142,144,146$ and 148. It is found that the crew members can be adjusted to 144 crew without exceeding the target flight time (See Figure 4). The crews' work schedule is busy, if at least 144 available cockpit crew members are assigned. However, it does not violate the minimum number of days off and the maximum flight time in every successive duty period. Ths, the crew members can be adjusted to 144 persons, if all reserves and duty have been assigned to the ground crew.

\section{Conclusions}

This study generates a Hybrid Scatter Search Algorithm to solve the crew rostering problem of Airbus A330 Garuda Indonesia. It considers some predetermined parameters, i.e., the number of seed solutions, reference sets, and maximum iterations. As the results, the proposed algorithm outperformed the trial and errors algorithm. The total deviation of 
flight time produced by the proposed algorithm is 1833.79 hours, which is $41.74 \%$ smaller than the total deviation of flight time produced by the trial and errors algorithm. Additionally, the proposed average crew flight time, 7.25 hours is $41.72 \%$ smaller than the existing algorithm. The sensitivity analysis revealed that the total standard deviation of cockpit crew flight time is increasing with the differences between the target and the average flight time. It means that the crew preference for a small crew member will not change the total standard deviation of flight time significantly since the flight time for each paired crew is relatively the same and flexible. Additionally, the number of flight time for each cockpit crew shall not exceed the maximum target of flight time by Garuda Indonesia, i.e., 110 hours for each crew in a month. It the available cockpit crew is limited, then the target can be adjusted to 144 hours.

\section{References}

1. El Moudani, W., Cosenza, C. A. N., de Coligny, M. and Mora-Camino, F., A Bicriterion Approach for the Airline Crew Rostering Problem, Lecture Notes in Computer Science 1993, 2001, pp. 486-500.

2. Kohl, N. and Karisch, S. E., Airline Crew Rostering: Problem Types, Modeling, and Optimization, Annals of Operations Research, Band 127, 2004, pp. 223-257.

3. Bazargan, M., Airline Operations and Scheduling. 2nd Hrsg. Burlington: Ashgate Publishing Company, 2010.

4. Barnhart, C., Airline Scheduling: Accomplishments, Opportunities and Challenges. In: The Integration of $A I$ and $O R$ Techniques in Constraint Programming for Combinatorial Optimization Problems (CPAIOR 2018), May 20-23, 2008, Paris, France.

5. Soykan, B., Erol, S., 2016. Airline operational Scheduling Process. In: The 3th International Aviation Management Conference, 19 April 2016, Ankara, Turkey, pp. 143-156.
6. Maenhout, B. and Vanhoucke, M., A Hybrid Scatter Search Heuristic for Personalized Crew Rostering in the Airline Industri, European Journal of Operations Research, Band 206, 2010, pp. 155-167.

7. Ernst, A. T., Jiang, H., Krishnamoorthy, M. and, Sier, D., Staff Scheduling and Rostering: A Review of Applications, Methods, and Models. European Journal of Operations Research, Band 153, 2004, pp. 3-27.

8. Abdelghany, A., and Abdelghany, K., Modeling ApplicAtions in the Airline industry. England: Ashgate publishing limited. 2009.

9. Yu, G., Operations Research in. Airline Industry. Dordrecht: Kluwer Academic Publishers, 1998.

10. Doi, T, Nishi, T, and Vob, S, Two-level Decomposition based Math Heuristic for Airline Crew Rostering Problems with Fair Working Time, European Journal of Operational Research, 2018, 2017, pp. 428-438.

11. Lucic P., Teodorovic, D., Metaheuristics Approach to The Aircrew Rostering Problem. Annals of Operations Research, 155(1), 2007, pp. 311338.

12. Glover, F. and Laguna, M., Fundamentals of Scatter Search and Path Eelinking, Control and Cybernetics, 3, 2000, pp. 653-684.

13. Yin, P. Y., Glover, F., Laguna, F. and Zhu, J.-X., Cyber Swam Optimization: Improving Particle Swam Optimization Using Adaptive Memory Strategies, European Journal of Operational Research, 201(2), 2010, pp. 377-389.

14. Laguna, M. and Marti, R., Scatter Search: Methodology and Implementations in C. Boston: Kluwer Academic Publishers, 2003.

15. PT Garuda Indonesia Tbk, Basic Operations Manual (BOM) Garuda Indonesia, Tangerang: Garuda Indonesia Airline, 2015.

16. PT Garuda Indonesia Tbk, 2015. Crew Pairing and Crew Rostering Data in October 2015. Tangerang: Garuda Indonesia Airline, 2015. 